\title{
Fate of Myclobutanil Residues after Application on Apples Growing to Korça District, Albania
}

\author{
Edlira Shahinasi ${ }^{1}$, Vojislava Bursic ${ }^{2}$, Martina Mezei ${ }^{2}$, Ferdi Brahushi ${ }^{3}$, Magdalena Cara $^{4}$ and Gorica Vukovic ${ }^{5}$ \\ 1. Department of Chemistry, Faculty of Biotechnology and Food, Agricultural University of Tirana, Tirana 1029, Albania \\ 2. Department of Environment and Plant Protection, Faculty of Agriculture, University of Novi Sad, Novi Sad 21000, Serbia \\ 3. Department of Agro-environment and Ecology, Faculty of Agriculture, Agricultural University of Tirana, Tirana 1029, Albania \\ 4. Department of Plant Protection, Faculty of Agriculture, Agricultural University of Tirana, Tirana 1000, Albania \\ 5. Institute of Public Health, Belgrade 112113, Serbia
}

\begin{abstract}
One of the largest and most important pesticides groups are Demthylation inhibitors, a class of single-side fungicides, used for the control of fungal diseases on fruit. The aim of this study was to investigate the fate of myclobutanil after its application in Starking and Golden Delicious cultivars. The apple trees were treated with maximum and minimum levels of recommended doses. The samples were collected randomly in different interval days after application. For identification and quantification of myclobutanil residues in apple fruit liquid chromatography-tandem mass spectrometry (LC-MS/MS) technique was performed. The highest values of myclobutanil residues were found at the $1^{\text {st }}$ day after treatment and by the time the residue levels were decreased. Thus, the level of myclobutanil residues ranges from $0.928 \mathrm{mg} \mathrm{kg}^{-1}$ to $0.019 \mathrm{mg} \mathrm{kg}^{-1}$ and from $2.085 \mathrm{mg} \mathrm{kg}^{-1}$ to $0.086 \mathrm{mg} \mathrm{kg}^{-1}$ in Starking treated with the minimum and maximum doses respectively. Also, in the Golden Delicious cultivar the level of myclobutanil residues ranges from $0.878 \mathrm{mg} \mathrm{kg}^{-1}$ to $0.026 \mathrm{mg} \mathrm{kg}$ and from $1.760 \mathrm{mg} \mathrm{kg}^{-1}$ to $0.092 \mathrm{mg} \mathrm{kg}^{-1}$ with the minimum and maximum applied doses at $1^{\text {st }}$ and $40^{\text {th }}$ day after application, respectively. Therefore, the samples treated with maximum recommended dose did not reach the MRL $\left(0.6 \mathrm{mg} \mathrm{kg}^{-1}\right)$ before the $14^{\text {th }}$ day after application, whereas the samples treated with minimum recommended dose reached MRL before 7th day after application. Therefore, the application of myclobutanil guarantees food safety for the consumer not only in minimum doses but even in maximal doses as well.
\end{abstract}

Key words: Apple, application doses, LC-MS/MS, myclobutanil, Korça district.

\section{Introduction}

The consumption of fruits and vegetables takes the second place on the food pyramid of many European countries, after the cearls.

Fruits and vegetables are considered good sources in fibers, vitamins, minerals in the form of electrolytes and antioxidants [1-3]. According to World Health Organization (WHO) [2] a diet rich in fruits and vegetables may reduce the risk of heart disease, prevent some type of cancer, promote weight loss by reducing the risk of obesity at the same time.

Among many fruit trees, apples are the most cultivated trees in Albania and the district of Korca

Corresponding author: Edlira Shahinasi M.Sc., research fields: environmental contaminants and food safety. represents the main market suplier in the country. It occupied around $70 \%$ of total area planted with fruits and $83 \%$ of total fruit production $[4,5]$.

Besides nutrient value and health benefits that fruits and vegetables possess, they can be sources of toxic substances if extensive pesticides are used during the control of plant diseases [3].

Among the most effective pesticides are the azoles or conazole, which are widely used for controlling of apple diseases. This group of fungicides belongs to demethylation inhibiter (DMI) fungicides which have a wide spectrum of activity [6].

Because this class of fungicides is used incrreasingly in many countries all over the world it is important to evaluate the fate of DMIs fungicides in fruits and environment [7]. The aim of this study was to 
determine presence of pesticide residues in apples and to assess if the fruits are safe for the consumers.

\section{Materials and Methods}

\subsection{Experimental Field and Sampling}

The experiment was conducted in Korça region as the main area of apple cultivation of apple in Albania, during 2015 and 2016. The experimental field was divided in four plots where two pots represented Golden Delicious apple trees and two others represented Starking apple trees. The pots were treated minimum and maximum recommended doses [8]. The orchard was treated in accordance with the guidelines of integrated production.

Thus, during the treatment with pesticides of apples were used solutions $0.025 \%$ and $0.015 \%$ of myclobutanil, which represent maximum and minimum recommended doses. The application of pesticides was done through a tractor in which two sprays were mounted. The samples were collected randomly in different interval days after application in accordance with European Commission Directive 2002/63/EC. All samples were placed in polythene bags, labelled and transported to the laboratory for further processing. Transportation and handling of apples was done through cooling boxes, the temperature of which did not exceed 5 to 6 degree Celsius.

\subsection{Extraction and Clean-up}

The extraction and purification of samples was based on QuEChERS method developed by Anasstasiades et al. [9] $10 \mathrm{~g}$ homogenized sample was weighted into a $50 \mathrm{~mL}$ polypropylene centrifuge tube followed by addition of $10 \mathrm{~mL}$ acetonitril $(\mathrm{MeCN})$ and $100 \mu \mathrm{L}$ internal standard (carbofuran d-3). After the samples were mixed by vortexing $4 \mathrm{~g}$ anhydrous sulfate $\left(\mathrm{MgSO}_{4}\right), 1 \mathrm{~g}$ sodium chloride $(\mathrm{NaCl}), 1 \mathrm{~g}$ trisodium citrate dihydrate, $0.5 \mathrm{~g}$ disodium hydrogencitrate sesquihydrate was added and the tubes were shaken again $1 \mathrm{~min}$ and then were centrifuged at $3,000 \mathrm{~g}$ for $5 \mathrm{~min}$. Six milliliter of upper layer (acetonitril extract) was transfered into a $15 \mathrm{~mL}$ PP centrifuge tube containing PSA sorbent and anhydrous sulfate. After the last centrifugation at $3,000 \mathrm{~g}$ the supernatant was filter and transferred in vial for LC-MS/MS analysis.

\subsection{Chemicals and LC-MS/MS Parameters}

All solvents were of chromatography grade and were purchased from J. T. Baker (Deventer, Netherland). The standard pesticides were purchased from Dr. Ehrenstorfer (Augsburg, Germany), most of them had the purity $\geq 98 \%$. Internal Standard (carbofuran d-3) was purchased from Pestanal, Fluka (Germany). Its purity was $99.7 \%$.

The analyses of pesticides were performed through the Agilent 1200 LC-MS/MS system (Agilent technology, USA) in positive mode Electrospray Ionization (+ESI). The mass analysis was carried out with an Agilent 6410 Triple Quadrupole mass spectrometer equipped with multi mode ion source. MassHunter Workstation B.06.00 (Agilent technology 2010) was used for instrument control and data collaction. The chromatography separation was carried out on a Zorbax Ecllipse XDB C18 column $(50 \times 4.6$ $\mathrm{mm}, 1.8 \mu \mathrm{m}$ ) maintained at $30^{\circ} \mathrm{C}$.

The mobile phase consisted of methanol $(30 \% \mathrm{v} / \mathrm{v})$ and Milli-Q water $(70 \% \mathrm{v} / \mathrm{v})$ acidified with formic acid (solution $0.1 \%$ ). Flow rate was set at 0.400 $\mathrm{mL} / \mathrm{min}$, the injection volume was $5 \mu \mathrm{L}$ and the run time $26 \mathrm{~min}$. The ESI source parameters were as follow: gas temperature $\left(\mathrm{N}_{2}\right) 325^{\circ} \mathrm{C}$, gas flow rate 5 $\mathrm{L} / \mathrm{min}$, nebulizer pressure $40 \mathrm{psi}$ and capillary voltage 2,000 v. The detection was performed using the multiple reactions monitoring mode (MRM).

\subsection{Calibration Curve}

Calibration curve was determined at five calibration level $0.005,0.01,0.025,0.05$ and $0.1 \mu \mathrm{g} \mathrm{mL}^{-1}$. Fig. 1 presents a good linearity with the correlation coefficient (R) above 0.99 . 


\section{Results and Discussion}

The obtained data on pesticide residues of the conducted experiment with application of myclobutanil in apple tree to control fungal disease on fruit were compared to the MRLs set in EU regulations.

The MRM chromatogram showed for myclobutanil a retention time equal to $17.588 \mathrm{~min}$. Confirmation and quantification of myclobutanil was done using $\mathrm{m} / \mathrm{z}$ 289.2 -> 70.2 dhe $m / z 289.2$->125.1 (Fig. 2).

Thus, the data presented in Table 1 and Fig. 3 showed that all the samples collacted immedialtely after the pesticide appliciaton had the highest level of myclobutanil residues and by the time a significant degradation of pesticide was observed.

Thus, the level of myclobutanil residues varies from $0.928 \mathrm{mg} \mathrm{kg}^{-1}$ to $0.019 \mathrm{mg} \mathrm{kg}^{-1}$ and from $2.085 \mathrm{mg} \mathrm{kg}^{-1}$ to $0.084 \mathrm{mg} \mathrm{kg}^{-1}$ in Starking with the minimum and maximum applied doses at $1^{\text {st }}$ and $40^{\text {th }}$ day after application, respectively.

Also, the data on Table 2 indicate that in the Golden Delicious cultivar the level of myclobutanil residues ranges from $0.878 \mathrm{mg} \mathrm{kg}^{-1}$ to $0.023 \mathrm{mg} \mathrm{kg}^{-1}$ and from $1.760 \mathrm{mg} \mathrm{kg}^{-1}$ to $0.055 \mathrm{mg} \mathrm{kg}^{-1}$ with the minimum and maximum applied doses at $1^{\text {st }}$ and $40^{\text {th }}$ day after application, respectively.

Therefore, the samples treated with maximum recommended dose did not reach the $\operatorname{MRL}\left(0.6 \mathrm{mg} \mathrm{kg}^{-1}\right)$ [10] before the $14^{\text {th }}$ day after application, meanwhile the samples treated with minimum recommended dose reached MRL before $7^{\text {th }}$ day after application (see Fig. 3 and Fig. 4).

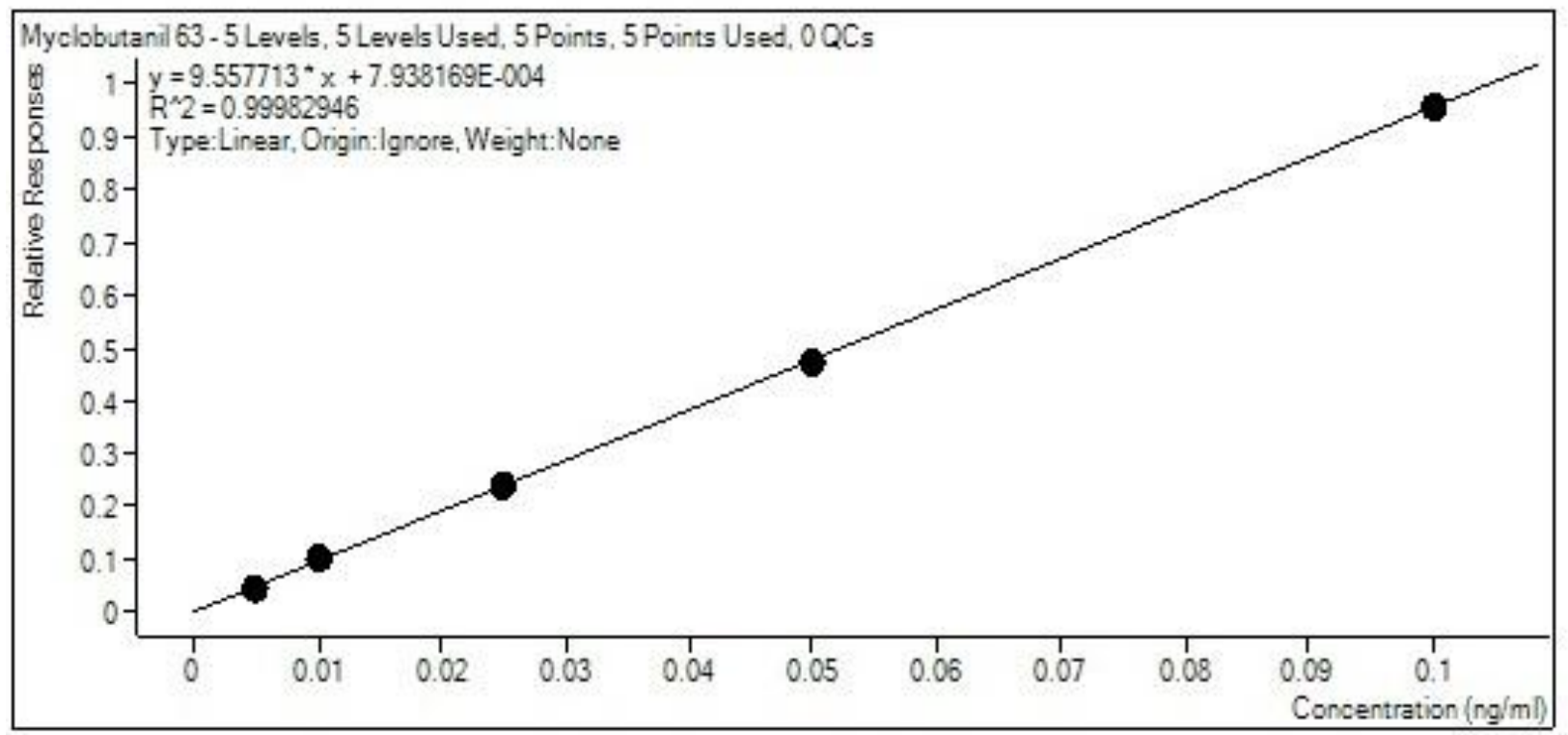

Fig. 1 Calibration curve of myclobutanil. 

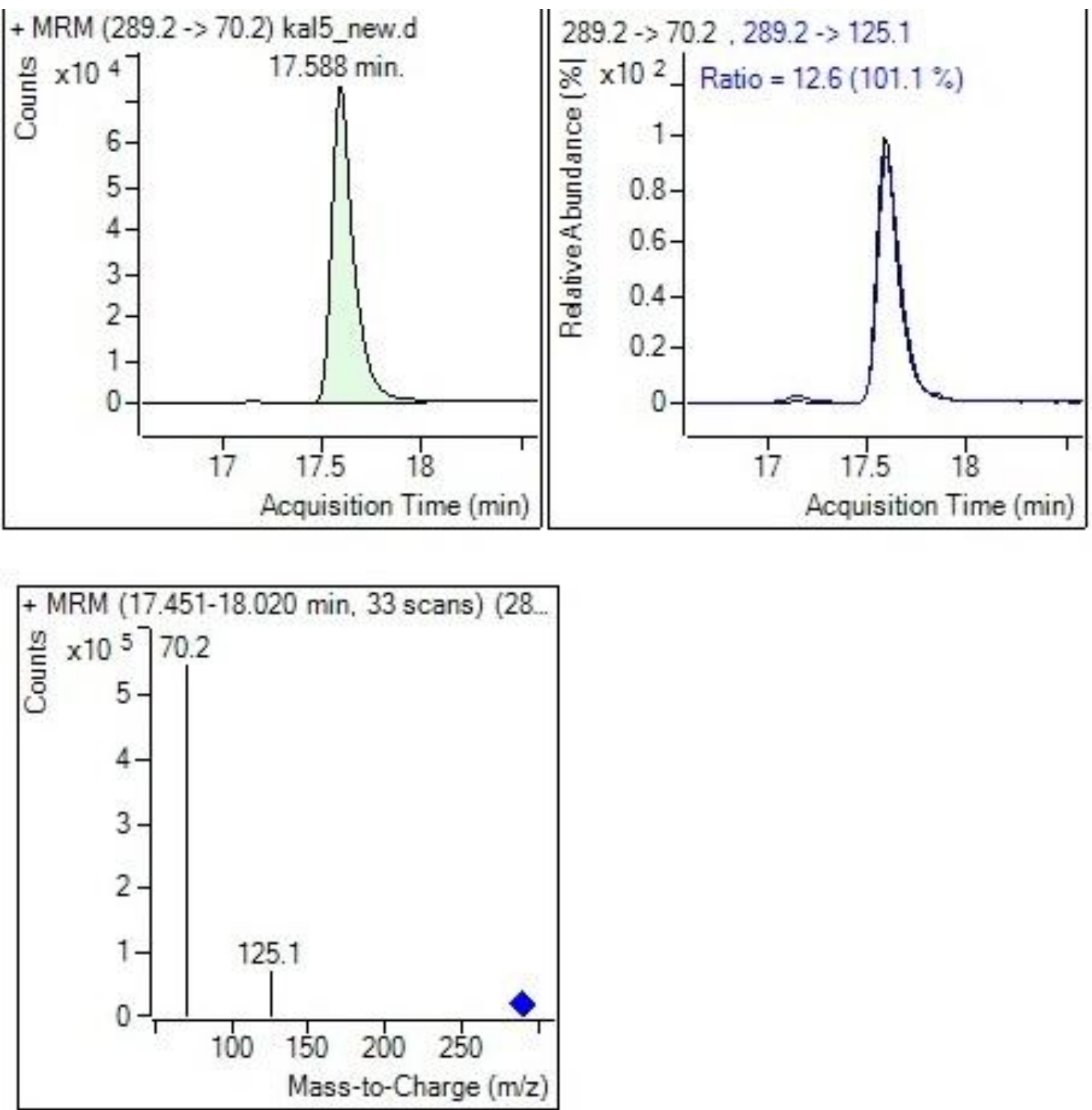

Fig. 2 MRM chromatogram of myclobutanil standard solution $\left(0.1 \mu \mathrm{g} \mathrm{L}^{-1}\right)$.

Table 1 Residues levels of myclobutanil $\left(\mathrm{mg} \mathrm{kg}^{-1}\right)$ in Starking cultivar.

\begin{tabular}{|c|c|c|c|c|c|c|}
\hline \multirow{3}{*}{ Days } & \multicolumn{3}{|c|}{ Starking min. } & \multicolumn{3}{|c|}{ Starking max. } \\
\hline & \multicolumn{2}{|c|}{ Year } & \multirow[t]{2}{*}{ Mean } & \multicolumn{2}{|c|}{ Year } & \multirow{2}{*}{ Mean } \\
\hline & 2015 & 2016 & & 2015 & 2016 & \\
\hline 1 & 0.920 & 0.936 & 0.928 & 2.012 & 2.159 & 2.085 \\
\hline 6 & 0.539 & 0.545 & 0.542 & 0.730 & 1.563 & 1.146 \\
\hline 14 & 0.197 & 0.339 & 0.268 & 0.419 & 0.747 & 0.583 \\
\hline 21 & 0.075 & 0.090 & 0.083 & 0.350 & 0.495 & 0.422 \\
\hline 28 & 0.034 & 0.023 & 0.028 & 0.104 & 0.218 & 0.161 \\
\hline 40 & 0.028 & 0.011 & 0.019 & 0.066 & 0.105 & 0.086 \\
\hline
\end{tabular}




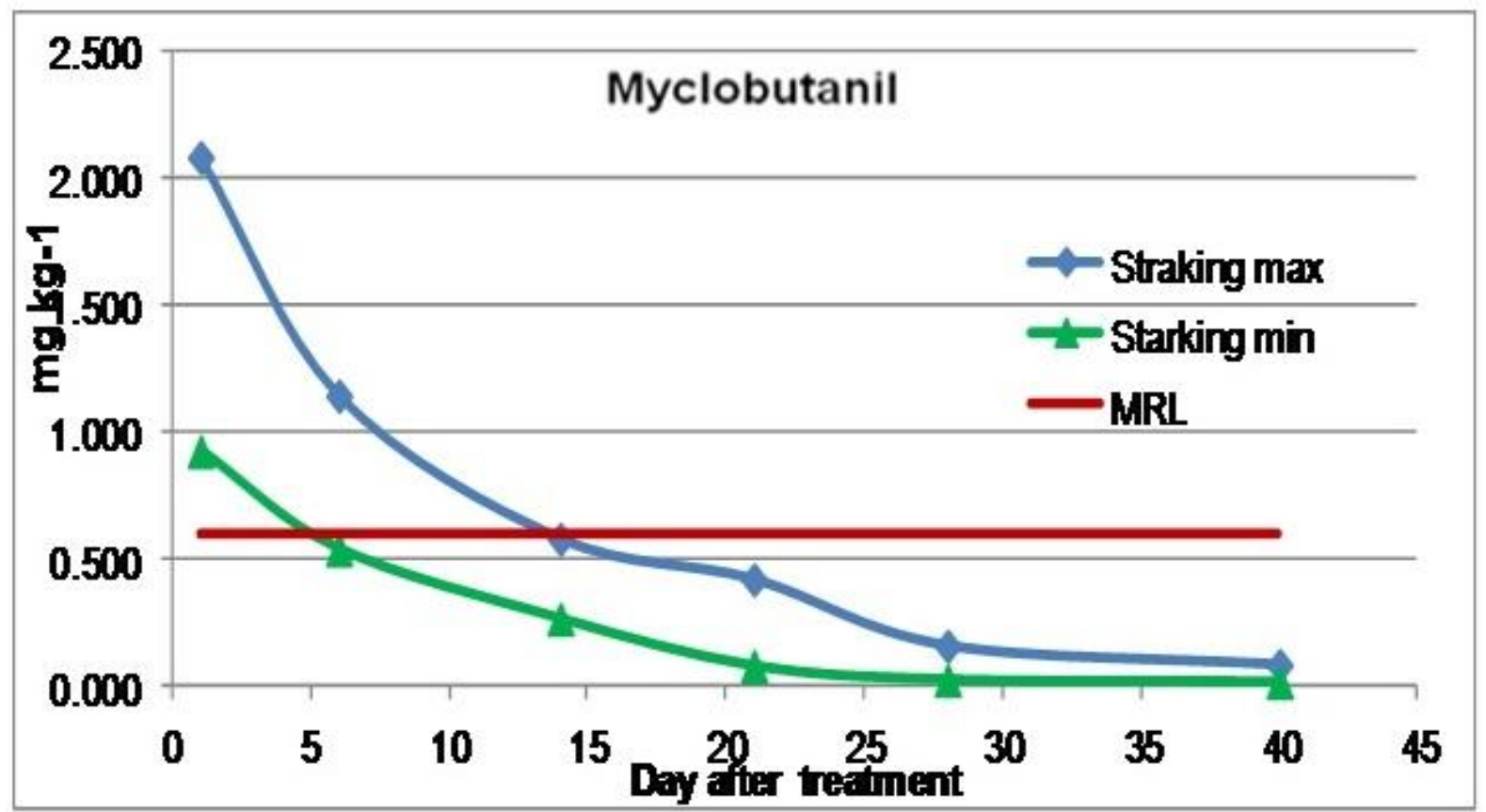

Fig. 3 Degradation of myclobutanil in Starking cultivar.

Table 2 Residues levels of myclobutanil $\left(\mathrm{mg} \mathrm{kg}^{-1}\right)$ in Golden Delicious cultivar.

\begin{tabular}{lllllll}
\hline & \multicolumn{3}{c}{ Golden min. } & \multicolumn{3}{c}{ Golden max. } \\
\cline { 2 - 6 } Days & \multicolumn{3}{c}{ Year } & Mean & Year & 2016 \\
\cline { 2 - 7 } & 2015 & 2016 & 0.878 & 1.734 & 1.785 & 1.760 \\
6 & 0.842 & 0.913 & 0.532 & 0.830 & 1.402 & 1.116 \\
14 & 0593 & 0.472 & 0.220 & 0.454 & 0.800 & 0.627 \\
21 & 0.268 & 0.173 & 0.064 & 0.311 & 0.479 & 0.395 \\
28 & 0.072 & 0.056 & 0.026 & 0.057 & 0.127 & 0.092 \\
40 & 0.026 & 0.025 & 0.022 & 0.040 & 0.070 & 0.055 \\
\hline
\end{tabular}




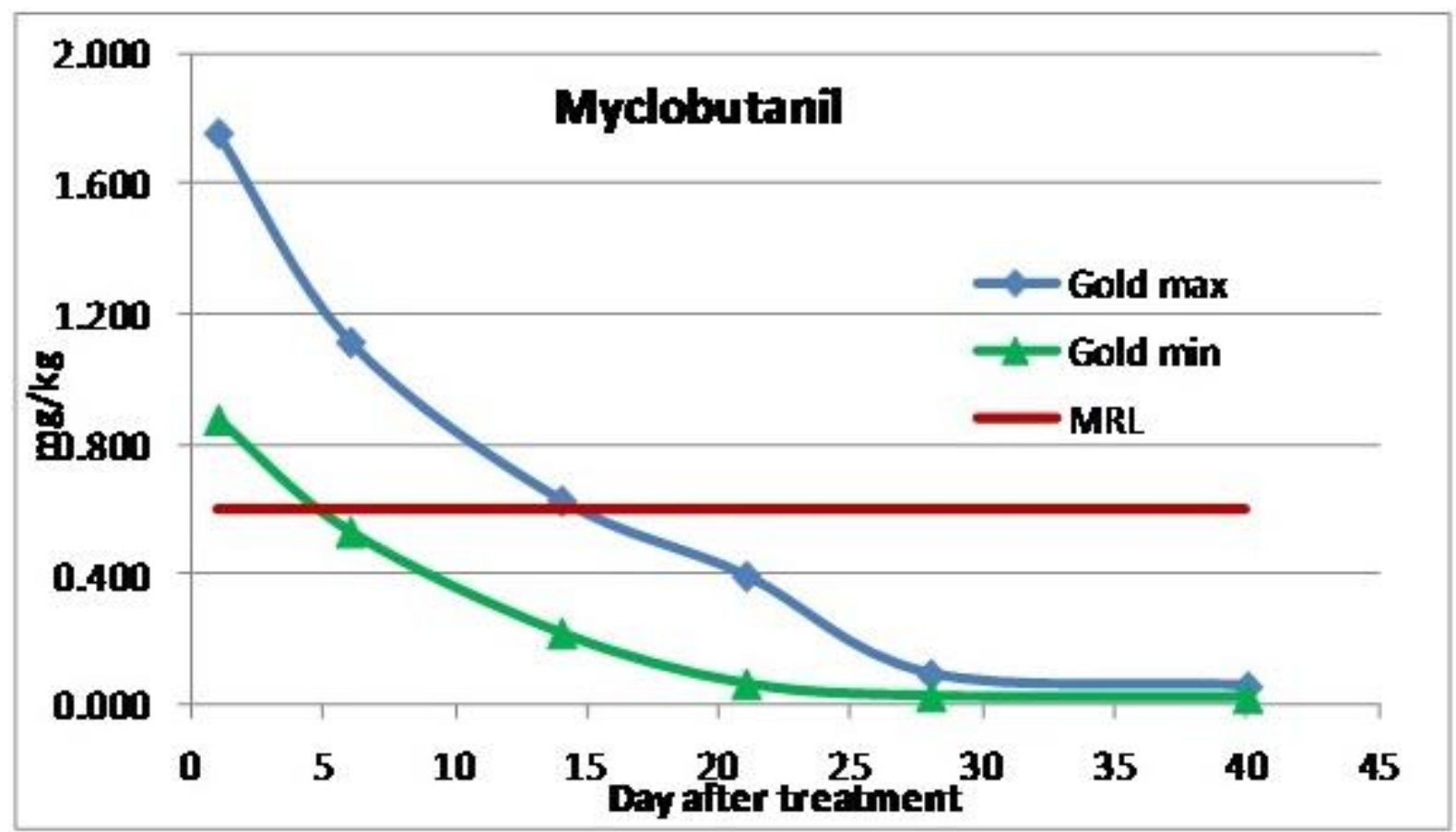

Fig. 4 Degradation of myclobutanil in Golden Delicious cultivar.

\section{Conclusions}

The obtained data showed that the level of myclobutanil residues in all analyzed samples decreased with the time. The level of myclobutanil residue in all samples on the first day after application was above Maximum Residues Levels $\left(0.6 \mathrm{mg} \mathrm{kg}^{-1}\right.$ apple fruit). The samples treated with maximum recommended dose reached the MRLs 15 days after application, whereas the samples treated with the minimum recommended dose reached the MRLs 2 time faster than those treated with maximum recommended dose.

In addition, the results of the experiment based on pre-harvest interval (PHI $=15$ days $)$ of myclobutanil guarantee food safety for the consumer in both minimum and maximum recommended doses.

\section{References}

[1] Pem, D., and Jeewon. R. 2015. "Fruit and Vegetable Intake: Benefits and Progress of Nutrition Education Interventions-Narrative Review Article." Iran J Public Health 24 (10): 1309-21.

[2] World Health Organization (WHO). 2014. "Increasing Fruit and Vegetable Consumption to Reduce the Risk of
Noncommunicable Diseases." e-Library of Evidence for Nutrition Actions. https://www.who.int/elena/titles/fruit_vegetables_ncds/en I.

[3] Szpyrka, E., Kurdziel, A., Matyaszek, A., Podbielska, M., Rupar, J., and Borowiec, S. M. 2015. "Evaluation of Pesticide Residues in Fruit and Vegetable from Region of South-Easten Poland.” J. Food Control 48: 137-42.

[4] Shahinasi, E., Brahushi, F., and Vladi, V. 2016. "Determination of Penconazole and Myclobutanil Residues in Apple." In Procceedings of the VII ${ }^{\text {th }}$ International Scientific Agricultural Symposium Jahorina, 1243-8.

[5] Kambo, A., and Osmani, M. 2018. “An Evaluation of Apple Production Waste in the Municipalities of Korça and Devoll and Some Related Issues." Albanian J. Agric. Sci. Special Edition-Procceedings of ICOALS, 739-45.

[6] Pfeufer, E. E., and Ngugi. K. H. 2012. "Orchard Factors Associeted with Resistence and Cross Resistence to Sterol Demethylation Inhibiter Fungicides in Populations of Venturia inaequalis from Pennsylvania." Phytopathology 102 (3): 272-82.

[7] Rueegg, J., and Siegfried, W. 1996. "Residues of Difenconazole and Penconazole on Apple Leaves and Grass and Soil in an Apple Orchard in North-Eastern Switzerland." Crop protection 15 (1): 27-31.

[8] Shahinasi, E., Bursic. V., Mezei, M., Brahushi, F., Vucovic, G., and Cara, M. 2018 "Degradation of Penconazole in Apple and Estimation of Residues Levels Using LC-MS/MS." In Procceedings of the International 
Agricultural, Biological \& Life Science Conference Edirne, 259-63.

[9] Anastassiades, M., Lehotay, S. J., Stajbaher, D., and Shneck, F. J. 2003. "Fast and Easy Multiresidue Method Emploing Acetonitril Extraction/Propotioning and Solid Phase Extraction for Determination of Pesticide Residues in Produce." Journal of AOAC International 86 (2): 412-31.

[10] EU Pesticides Database. 2005. Regulation (EC) No. 396. http://ec.europa.eu/food/plant/pesticides/eu-pesticides-dat abase/public/?event=pesticide.residue.CurrentMRL\&lang uage $=\mathrm{EN}$. 